\title{
Effect of Glass Composition on Chemical Reaction between Lead Zirconate Titanate and Glasses (Part 2) \\ Lead-silicate and Lead-borosilicate Glasses_-
}

\author{
Bambang Sunendar PURWASASMITA and Toshio KIMURA \\ Department of Materials Science, Faculty of Science and Technology, Keio University, 3-14-1, Hiyoshi, Kohoku-ku, Yokohama-shi 223-8522
}

\section{ジルコン酸チタン酸鉛とガラスの化学反応に及ぼすガラス組成の影響（第 2 報） —ケイ酸鉛ガラスとホウケイ酸鉛ガラス——}

\author{
Bambang Sunendar Purwasasmita · 木村敏夫 \\ 慶應義塾大学大学院理工学研究科, 223-8522 横浜市港北区日吉 3-14-1
}

\begin{abstract}
The products of reaction between $\mathrm{Pb}\left(\mathrm{Z}_{\mathrm{r}_{0.53}} \mathrm{Ti}_{0.47}\right) \mathrm{O}_{3}(\mathrm{PZT})$ and glasses in the $\mathrm{PbO}-\mathrm{SiO}_{2}$ and $\mathrm{PbO}-\mathrm{B}_{2} \mathrm{O}_{3}-\mathrm{SiO}_{2}$ systems at $850^{\circ} \mathrm{C}$ were studied using powder and bulk PZT samples. A reaction zone was formed between bulk PZT and the glass. The microstructure of the reaction zone changed with the amount of PZT dissolved in the glass phase, which was dependent on the activity of $\mathrm{PbO}$ in both the glass phase and $\mathrm{PZT}$. When the amount of dissolved PZT was small, as in the reaction between $\mathrm{PZT}$ and $60 \mathrm{~mol} \% \mathrm{PbO} \cdot 40 \mathrm{~mol} \% \mathrm{SiO}_{2}$ glass, the glass phase penetrated into grain boundaries of PZT, and no solid reaction product was formed. When the amount of dissolved PZT was intermediate, as in that between PZT and $40 \mathrm{~mol} \% \mathrm{PbO} \cdot 60 \mathrm{~mol} \% \mathrm{SiO}_{2}$ glass, the glass phase penetrated into the $\mathrm{PZT}$ pellet and $\mathrm{ZrO}_{2}$ particles were precipitated in the glass phase. When the amount of dissolved PZT was large, as in those between PZT and $60 \mathrm{~mol} \% \mathrm{PbO} \cdot 20 \mathrm{~mol} \% \mathrm{~B}_{2} \mathrm{O}_{3} \cdot 20$ $\mathrm{mol}_{\%} \mathrm{SiO}_{2}$ glass and $40 \mathrm{~mol} \% \mathrm{PbO} \cdot 30 \mathrm{~mol} \% \mathrm{~B}_{2} \mathrm{O}_{3} \cdot 30 \mathrm{~mol} \% \mathrm{SiO}_{2}$ glass, the reaction zone was formed, which was composed of Ti-rich $\mathrm{PZT}$ and $\mathrm{ZrO}_{2}$ particles dispersed in the glass phase.
\end{abstract}

[Received March 27, 2000; Accepted September 20, 2000]

Key-words : Lead zirconate titanate, Lead-silicate glass, Lead-borosilicate glass, Interfacial reaction, Powder reaction, Reaction product, Reaction mechanism

\section{Introduction}

Glasses are an important material in the application of dielectric and piezoelectric ceramics, and the chemical interaction between ceramics and glasses must be understood to design the ceramic devices. In the preceding paper (Part 1), ${ }^{1}$ we examined the chemical reaction between $\mathrm{Pb}\left(\mathrm{Zr}_{0.53}\right.$ $\left.\mathrm{Ti}_{0.47}\right) \mathrm{O}_{3}$ (PZT) and $\mathrm{PbO}-\mathrm{B}_{2} \mathrm{O}_{3}$ glasses. In this paper, we used the glasses in the $\mathrm{PbO}-\mathrm{SiO}_{2}$ and $\mathrm{PbO}-\mathrm{B}_{2} \mathrm{O}_{3}-\mathrm{SiO}_{2}$ systems. The same experimental methods as those used in Part 1 , using powder and bulk PZT, were employed in this work. We will mainly deal with the reaction products and microstructure of the reaction zone between bulk PZT and glasses.

\section{Experimental procedures}

The detailed experimental procedures were described in the preceding paper. ${ }^{1)}$ Here, the procedures are briefly described. PZT powder was prepared by heating the mixture of $\mathrm{PbO}, \mathrm{TiO}_{2}$, and $\mathrm{ZrO}_{2}(1.00: 0.53: 0.47$ in the molar ratio) at $885^{\circ} \mathrm{C}$ for $4 \mathrm{~h}$. Part of the resultant PZT powder was used in the powder reaction experiment. The remaining powder was used to prepare sintered disks by heating at $1100^{\circ} \mathrm{C}$ for $1.5 \mathrm{~h}$. Lead-silicate and lead-borosilicate glass powders were prepared by melting the mixtures of $\mathrm{PbO}$, $\mathrm{SiO}_{2}$, and $\mathrm{B}_{2} \mathrm{O}_{3}$ powders in platinum crucibles at $1200^{\circ} \mathrm{C}$ for $1.5 \mathrm{~h}$, quenching, and stamp-milling. The nominal composition is expressed in mol\%; $40 \% \mathrm{PbO} \cdot 60 \% \mathrm{SiO}_{2}(\mathrm{PS} 40), 60$ $\% \mathrm{PbO} \cdot 40 \% \mathrm{SiO}_{2}(\mathrm{PS} 60), 40 \% \mathrm{PbO} \cdot 30 \% \mathrm{~B}_{2} \mathrm{O}_{3} \cdot 30 \% \mathrm{SiO}_{2}$ (PBS40), and $60 \% \mathrm{PbO} \cdot 20 \% \mathrm{~B}_{2} \mathrm{O}_{3} \cdot 20 \% \mathrm{SiO}_{2}$ (PBS60).

Green compacts of the mixtures of PZT and glass powders (PZT : glass $=1: 1$ by weight unless otherwise stated) and PZT pellets buried in the glass powder were heated in a furnace kept at $850^{\circ} \mathrm{C}$. The glasses used in this experiment must be completely melted at this temperature, as judged from the phase diagrams. ${ }^{2), 3)}$ After heating for $30 \mathrm{~min}$, the samples were cooled slowly in the furnace or quickly by quenching in air. In some experiments, $\mathrm{PbZrO}_{3}$ and $\mathrm{PbTiO}_{3}$ powders were used in the powder reaction. The phases present were identified by the X-ray diffraction (XRD) analysis, and microstructure and distribution of elements were observed with a scanning electron microscope (SEM) and electron-probe X-ray microanalyzer (EPMA), respectively.

\section{Results and discussion}

3.1 Lead-silicate glasses

The microstructure of interfacial region between the PZT pellet and glass was changed with the glass composition and cooling rate. Figure 1 shows the microstructure of interfacial regions of PZT pellet-PS40 glass and PZT pellet-PS60 glass. The microstructure shown in Fig. 1(a) is PZT/PS40 cooled quickly. The same microstructure was obtained by slow-cooling, indicating that the cooling rate gave a small effect on the microstructure in this sample. The glass dissolved PZT grains and penetrated into the PZT pellet. The penetration of glass was not uniform. Probably, the PZT pellet was not completely homogeneous, and the dissolution rate was dependent on the position. In the glass phase penetrating into the PZT pellet, small black particles are observed.

The PS60 glass gave different microstructure and the microstructure was influenced by a cooling rate. The glass penetrated into the PZT pellet by dissolving grain boundaries. No solid product formed in the sample cooled quickly (Fig. 1(b)), but black materials were present at the interfacial region between $\mathrm{PZT}$ and the glass phase in the sample cooled slowly (Fig. 1(c)); the black materials precipitated during cooling.

The mechanisms of formation of the interfacial micro- 

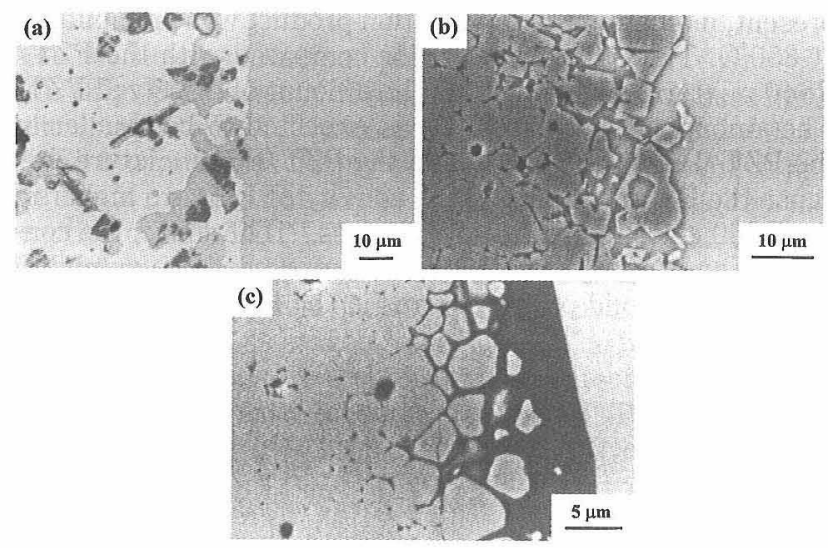

Fig. 1. SEM microphotographs of the PZT/PS40 (a) and PZT/ PS60 (b) samples cooled quickly and the PZT/PS60 sample (c) cooled slowly, obtained by the reaction between PZT pellet and glass. The left- and right-hand sides are PZT and glass, respectively.

structure were examined from the EPMA and XRD results using bulk and powder PZT, respectively.

PZT/PS40: Figure 2 shows the EPMA result of the PZT/ PS40 sample obtained by the reaction between the PZT pellet and glass. The areas with the presence of $\mathrm{Si}$ and absence of $\mathrm{T} i$ in the PZT pellet indicate the penetrating glass phase. The Si concentration decreased as the depth of penetration increased, for which the dissolution of PZT was responsible. $\mathrm{Zr}$-rich and $\mathrm{Pb}-, \mathrm{Ti}$ - and Si-poor areas are present in the penetrating glass phase, indicating that the black particles in Fig. 1(a) are mainly composed of $\mathrm{ZrO}_{2}$.

Figure 3(a) shows the XRD pattern of the PZT/PS40 powder mixture ( $1: 1$ by weight) heated at $850^{\circ} \mathrm{C}$ for $30 \mathrm{~min}$ and cooled quickly. Several new diffraction lines in addition to those of PZT were present, indicating the formation of a new compound. The same new lines were observed in the XRD pattern (Fig. 3(b)) of the $\mathrm{PbZrO}_{3} / \mathrm{PS} 40$ powder mixture ( $1: 1$ by weight) treated by the same heating program, but they were not observed in the $\mathrm{PbTiO}_{3} / \mathrm{PS} 40$ powder mixture (1:1 by weight) (Fig. 3(c)). No compounds having the same diffraction lines as this reaction product were found in the JCPDS data files. Probably, the reaction product is a compound in the $\mathrm{PbO}-\mathrm{SiO}_{2}-\mathrm{ZrO}_{2}$ system. This compound will be referred to as phase $\mathrm{X}$.

The product of powder reaction was dependent on the mixing ratio of $\mathrm{PZT}$ or $\mathrm{PbZrO}_{3}$ to $\mathrm{PS} 40$. Figure 3 (d) shows the XRD pattern of the $\mathrm{PbZrO}_{3} / \mathrm{PS} 40$ powder mixture $(2: 1$ by weight) heated at $850^{\circ} \mathrm{C}$ for 30 min and cooled quickly. In this case, the reaction product was $\mathrm{ZrO}_{2}$ as well as phase X.

Phase $\mathrm{X}$ and $\mathrm{ZrO}_{2}$ were formed in the $\mathrm{PbZrO}_{3} / \mathrm{PS} 40$ powder mixtures. However, it is impossible for both of these two phases to be stable phases in equilibrium with $\mathrm{PbZrO}_{3}$ and glass melt, as judged from the phase rule. The degree of freedom $(F)$ available to the system under constant pressure is determined by $F=C-P+1$, where $C$ is the number of components and $P$ is the number of equilibrium phases. For the present system $\left(\mathrm{PbZrO}_{3}-\mathrm{PbO}-\mathrm{SiO}_{2}\right), \mathrm{C}=3$. When $\mathrm{PbZrO}_{3}$, glass melt, $\mathrm{ZrO}_{2}$, and phase $\mathrm{X}$ are equilibrium phases and coexist as in the sample shown in Fig. 3(d), the degree of freedom is zero. However, the coexistence of four phases $\left(\mathrm{PbZrO}_{3}\right.$, glass melt, $\mathrm{ZrO}_{2}$, and phase $\left.\mathrm{X}\right)$ was observed in the $\mathrm{PbZrO}_{3} / \mathrm{PS} 40$ samples heated between $800^{\circ}$ and $850^{\circ} \mathrm{C}$ and quenched. Therefore, both phase $\mathrm{X}$ and $\mathrm{ZrO}_{2}$ are not the stable phases in equilibrium with $\mathrm{PbZrO}_{3}$ and glass melt.
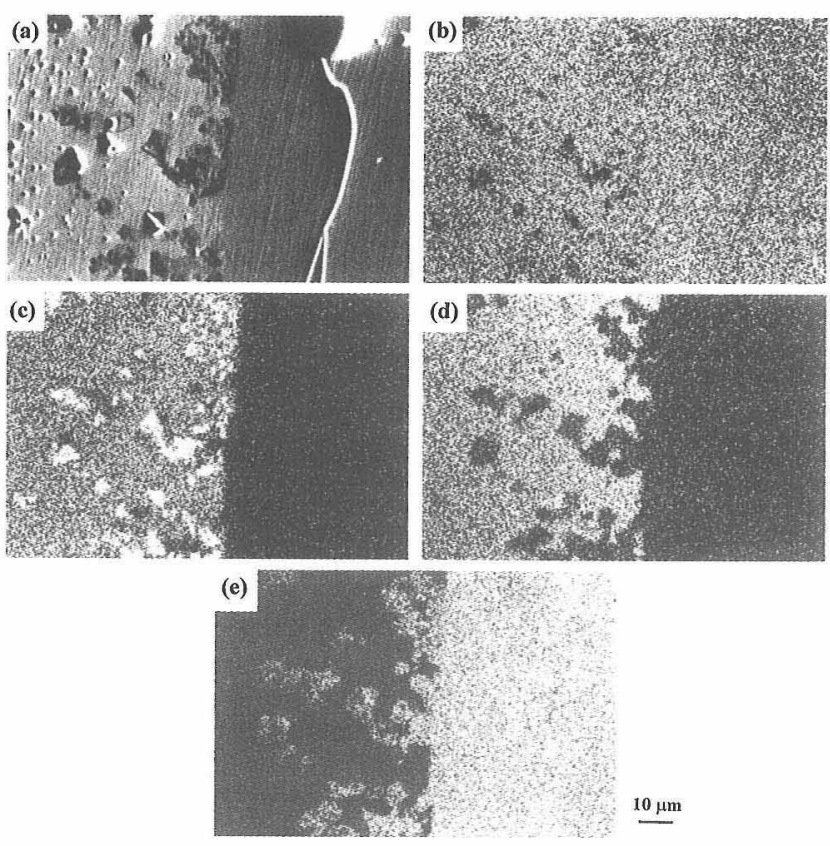

Fig. 2. Microstructure (a) and distribution of $\mathrm{Pb}(\mathrm{b}), \mathrm{Zr}$ (c), Ti (d), and Si (e) in the PZT/PS40 sample cooled quickly, obtained by the reaction between PZT pellet and glass. The left- and righthand sides are PZT and glass, respectively.

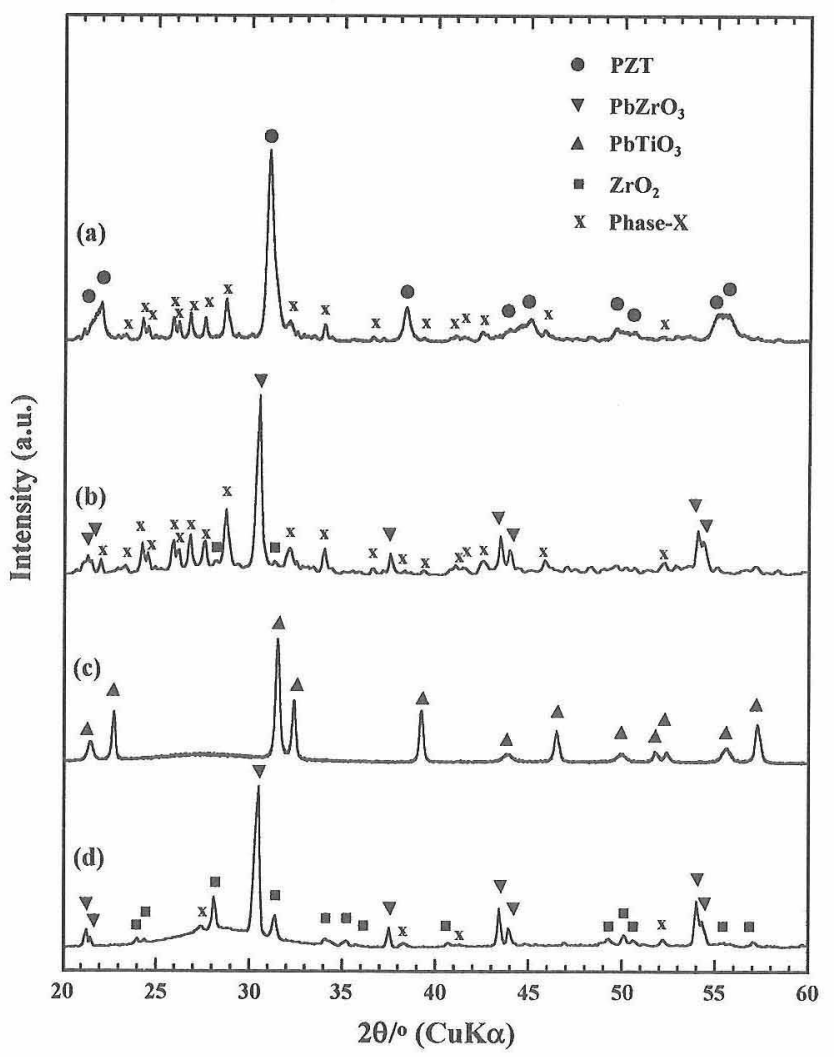

Fig. 3. XRD patterns of products in the powder reaction between PS40 and $\mathrm{PZT}(\mathrm{a}), \mathrm{PbZrO}_{3}$ (b) , and $\mathrm{PbTiO}_{3}$ (c) with the mixing ratio 1 : 1 by weight and between $\mathrm{PS} 40$ and $\mathrm{PbZrO}_{3}$ (d) with the mixing ratio $1: 2$. All samples were cooled quickly.

$\mathrm{ZrO}_{2}$ is probably metastable as compared with phase $\mathrm{X}$. When PZT or $\mathrm{PbZrO}_{3}$ dissolves in the glass melt, the con- 
stituent oxides dissolve completely and the $\mathrm{ZrO}_{2}$ concentration exceeds the solubility limit. In general, the solubility of metastable phase is larger than that of stable phase. Therefore, at small supersaturation, the concentration of a precipitating component exceeds the solubility limit with respect to the stable phase but stays within the solubility limit with respect to the metastable phase. In the present case, the $\mathrm{ZrO}_{2}$ concentration is smaller in the $\mathrm{PbZrO}_{3} / \mathrm{PS} 40$ mixture with the ratio $1: 1$ than that with the ratio $2: 1$. Phase $\mathrm{X}$ precipitated in the former mixture. Thus, phase $\mathrm{X}$ is judged to be more stable phase.

From above discussion, it is possible that $\mathrm{ZrO}_{2}$ and phase $\mathrm{X}$ are precipitated from glass melt with high and low $\mathrm{ZrO}_{2}$ concentration, respectively. However, the supersaturation, not the $\mathrm{ZrO}_{2}$ concentration, determines the precipitation behavior. Therefore, we will use the degree of supersaturation, in stead of the $\mathrm{ZrO}_{2}$ concentration, in the explanation of the precipitation of reaction products.

The mechanism of formation of the interfacial microstructure (Fig. 1(a)) can be explained as follows. PZT dissolves in the PS40 glass melt, but the dissolution rate is dependent on the characteristics of PZT grains. The glass melt penetrates into PZT by dissolving grain boundaries. In the penetrating glass melt, the concentration of $\mathrm{PbO}, \mathrm{ZrO}_{2}$, and $\mathrm{TiO}_{2}$ increases. The solubility of $\mathrm{ZrO}_{2}$ and $\mathrm{TiO}_{2}$ in the glass melt is estimated from the glass-forming regions in the $\mathrm{PbO}-\mathrm{SiO}_{2}-\mathrm{ZrO}_{2}$ and $\mathrm{PbO}-\mathrm{SiO}_{2}-\mathrm{TiO}_{2}$ systems (Fig. 4);4) $\mathrm{TiO}_{2}$ has larger solubility than $\mathrm{ZrO}_{2}$. Thus, while $\mathrm{TiO}_{2}$ can continue to dissolve in the glass melt but the $\mathrm{ZrO}_{2}$ concentration exceeds the solubility limit. In the penetrating glass melt, the relative amount of PZT to PS40 is large and therefore the degree of supersaturation is large, resulting in the precipitation of $\mathrm{ZrO}_{2}$ particles.

PZT/PS60: Figure 5 shows the EPMA result of the slowly-cooled PZT/PS60 sample obtained by the reaction between the PZT pellet and glass. The black materials were composed of $\mathrm{Pb}, \mathrm{Zr}$, and $\mathrm{Si}$.

Figure 6 shows the XRD patterns of the products of powder reaction at $850^{\circ} \mathrm{C}$ for $30 \mathrm{~min}$. In the sample cooled quickly (Fig. 6(a)), no crystalline phase except for PZT was

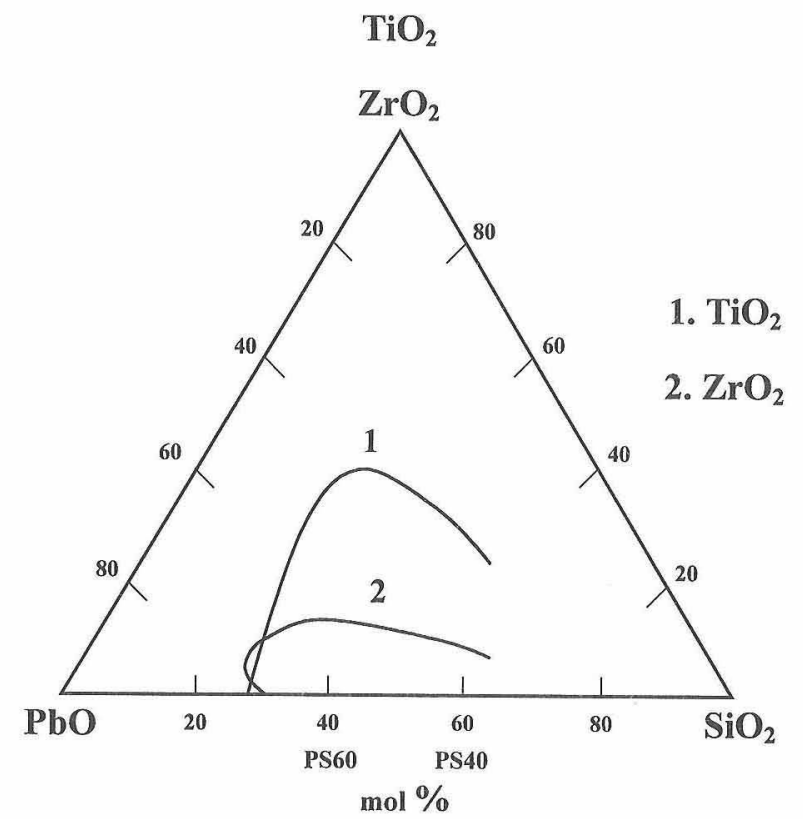

Fig. 4. Glass-forming regions in the $\mathrm{PbO}-\mathrm{SiO}_{2}-\mathrm{TiO}_{2}$ and $\mathrm{PbO}-\mathrm{SiO}_{2}-\mathrm{ZrO}_{2}$ systems. present, indicating that no reaction product was precipitated at $850^{\circ} \mathrm{C}$. The different behavior compared with the PZT/ PS40 mixture is explained by the amount of dissolved PZT. The amount of dissolved PZT is expected to be smaller in the PZT/PS60 mixture than in the PZT/PS40 mixture, because the $\mathrm{PbO}$ content and the activity of $\mathrm{PbO}$ are higher in the PS60 glass than in the PS40 glass. ${ }^{1)}$ Therefore, the concentration of $\mathrm{ZrO}_{2}$ and $\mathrm{TiO}_{2}$ does not exceed the solubility limit, and no solid product forms in the PZT/PS60 mixture
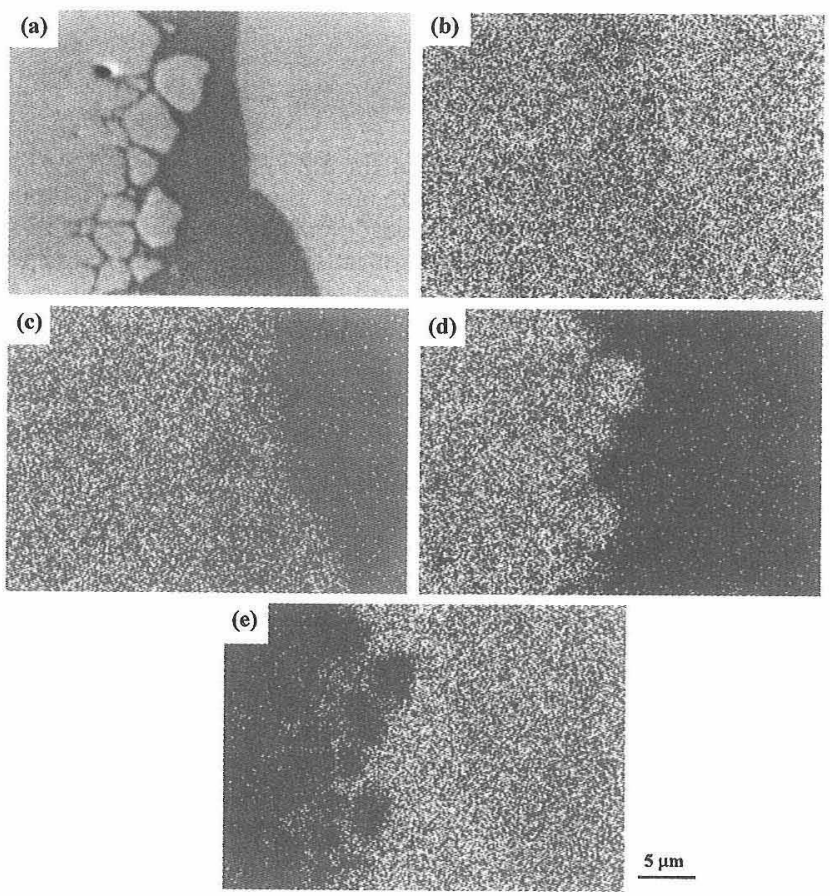

Fig. 5. Microstructure (a) and distribution of $\mathrm{Pb}$ (b), $\mathrm{Zr}$ (c), $\mathrm{Ti}(\mathrm{d})$, and $\mathrm{Si}(\mathrm{e})$ in the PZT/PS60 sample cooled slowly, obtained by the reaction between PZT pellet and glass. The left- and righthand sides are PZT and glass, respectively.

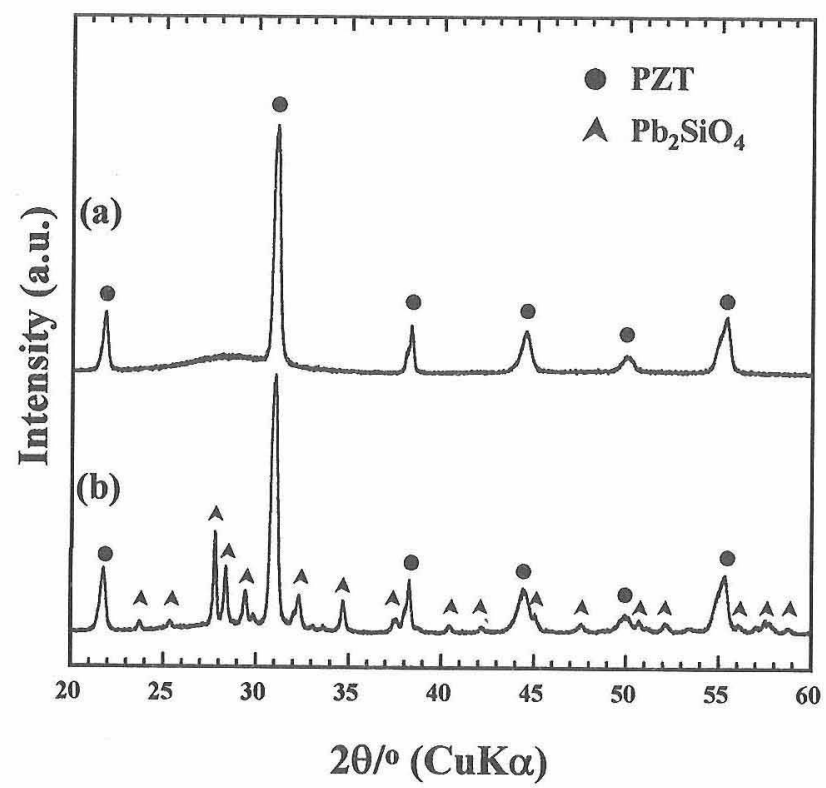

Fig. 6. XRD patterns of products in the powder reaction between PS60 and PZT ( $1: 1$ by weight) cooled quickly (a) and slowly (b). 
at $850^{\circ} \mathrm{C}$.

In the slowly-cooled sample obtained by the powder reaction (Fig. 6(b)), new diffraction lines appeared. These lines belong to $\mathrm{Pb}_{2} \mathrm{SiO}_{4}$, , indicating that a small amount of $\mathrm{Pb}_{2} \mathrm{SiO}_{4}$ crystallizes during cooling. ${ }^{6)}$ This compound is not the black materials observed in the sample obtained by the reaction of bulk PZT (Fig. 1(c)), because the black materials contain $\mathrm{Zr}$ and the concentration of $\mathrm{Pb}$ and $\mathrm{Si}$ in the black materials is lower and higher than that in the glass phase (60 mol\% PbO), as judged from Fig. 5. The black materials may be phase $\mathrm{X}$, even though it is not detected by XRD in the product of powder reaction (Fig. 6(b)). The constituent oxides of PZT completely dissolve in the glass melt at $850^{\circ} \mathrm{C}$ until the activity of $\mathrm{PbO}$ in the glass melt reaches that in PZT. During cooling, the solubility of $\mathrm{ZrO}_{2}$ decreases as the temperature decreases, and phase $\mathrm{X}$ precipitates under the small degree of supersaturation.

The concentration of the constituent oxides of PZT dissolved in the glass melt probably determines the solid product in the slowly-cooled samples. In the sample obtained by the reaction of bulk PZT, the relative amount of PZT to PS60 is large and the concentration of $\mathrm{ZrO}_{2}$ is high as compared with that in the sample obtained by the powder reaction, resulting in the formation of phase X during cooling. In the sample obtained by the powder reaction, on the other hand, the relative amount of PZT to PS60 is small and the concentration of $\mathrm{ZrO}_{2}$ is low. Thus, the rate of precipitation of phase $\mathrm{X}$ is small. The rate of crystallization might be increased by the introduction of $\mathrm{TiO}_{2}$ and/or $\mathrm{ZrO}_{2}$, and $\mathrm{Pb}_{2} \mathrm{SiO}_{4}$ forms in the sample obtained by the powder reaction (the PS60 glass itself did not crystallize by slow-cooling).

\subsection{Lead-borosilicate glasses}

Figure 7 shows the microstructure of interfacial region of the PZT/PBS40 and PZT/PBS60 samples obtained by the reaction between the PZT pellet and glass.

PZT/PBS40: The microstructure shown in Fig. 7(a) is PZT/PBS40 cooled quickly. The same microstructure was obtained by slow-cooling, indicating that the cooling rate gave a small effect on the microstructure. The reaction zone similar to that observed between PZT and the $40 \mathrm{~mol} \%$ $\mathrm{PbO} \cdot 60$ mol\% $\mathrm{B}_{2} \mathrm{O}_{3}$ glass (PB40) (Fig. 8 of Part $1^{1)}$ ) developed between PZT and the glass phase. The reaction zone was composed of two layers; layer I contained white and

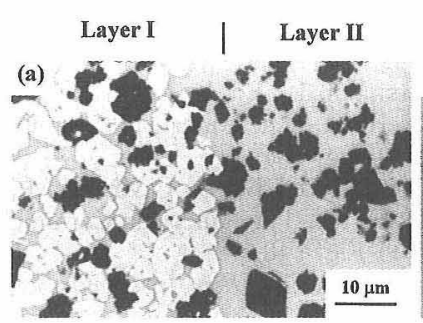

(c)

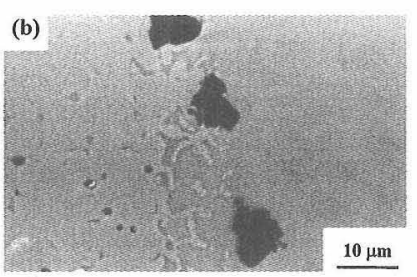

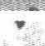

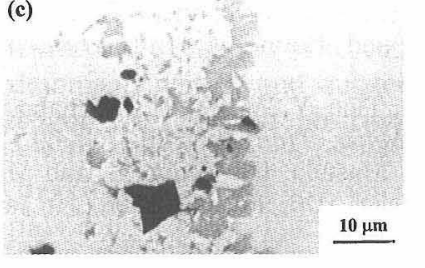

Fig. 7. SEM microphotographs of the PZT/PBS40 (a) and PZT/ PBS60 (b) samples cooled quickly and the PZT/PBS60 sample (c) cooled slowly, obtained by the reaction between PZT pellet and glass. The left- and right-hand sides are PZT and glass, respectively. black particles and layer II contained black particles. The white and black particles are Ti-rich PZT and $\mathrm{ZrO}_{2}$, respectively, as in the case of the PZT/PB40 sample (the EPMA result is not shown here). The formation mechanism of the zone is the same as that of PZT/PB40.1)

PZT/PBS60: The microstructure of the PZT/PBS60 sample obtained by the reaction between the PZT pellet and glass was dependent on the cooling rate. The glass melt dissolved PZT and penetrated into grain boundaries of PZT and black particles were formed in the sample cooled quickly (Fig. 7(b)). Figure 8 shows the EPMA result, indicating that the black particles are $\mathrm{ZrO}_{2}$ particles. Figure 9 shows the XRD pattern of the product of powder reaction between PZT and PBS 60 heated at $850^{\circ} \mathrm{C}$ for $30 \mathrm{~min}$ and cooled quickly. The diffraction lines of $\mathrm{ZrO}_{2}$ were confirmed. Furthermore, the comparison between Figs. 9 and 6 (a) indicates that the $c / a$ ratio of PZT in the PZT/PBS60 mixture is larger than that of PZT in the PZT/PS60 mixture. These
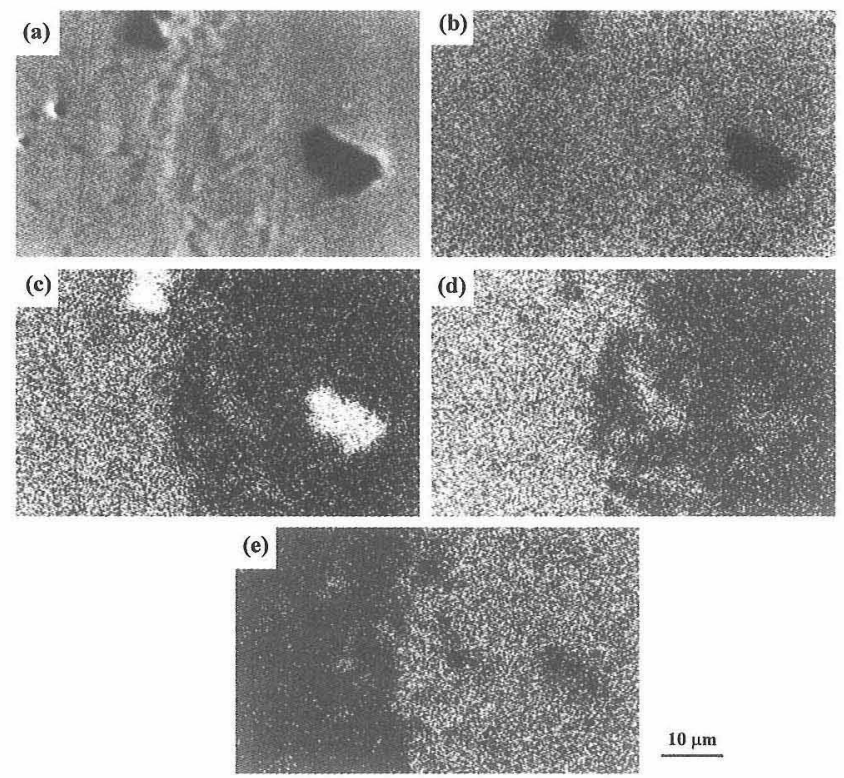

$\underline{10 \mu \mathrm{m}}$

Fig. 8. Microstructure (a) and distribution of $\mathrm{Pb}$ (b), $\mathrm{Zr}$ (c), $\mathrm{Ti}$ (d), and Si (e) in the PZT/PBS60 sample cooled quickly, obtained by the reaction between PZT pellet and glass. The left- and right-hand sides are PZT and glass, respectively.

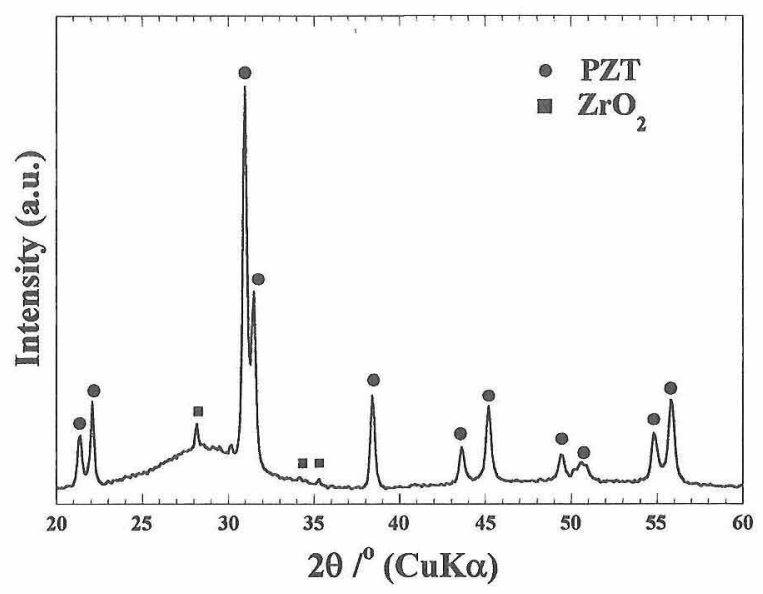

Fig. 9. XRD pattern of product in the powder reaction between PBS60 and PZT (1:1 by weight) cooled quickly. 

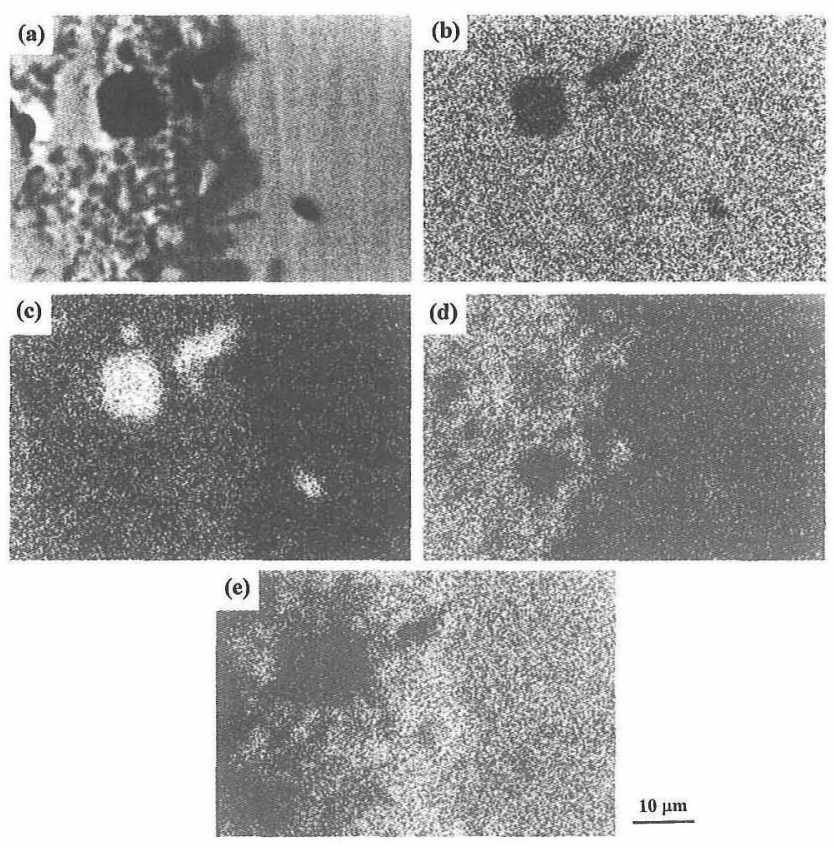

Fig. 10. Microstructure (a) and distribution of $\mathrm{Pb}(\mathrm{b}), \mathrm{Zr}$ (c), $\mathrm{Ti}$ (d), and $\mathrm{Si}$ (e) in the PZT/PBS60 sample cooled slowly, obtained by the reaction between PZT pellet and glass. The left- and right-hand sides are PZT and glass, respectively.

results indicate that the solid reaction products are Ti-rich PZT and $\mathrm{ZrO}_{2}$. The PBS60 melt dissolves grain boundaries of PZT and penetrated into the PZT pellet. The concentration of the constituent oxides of PZT increases in the glass melt, and Ti-rich $\mathrm{PZT}$ and $\mathrm{ZrO}_{2}$ precipitate, as in the case of PZT/PBS40 sample.

In the slowly-cooled PZT/PBS60 sample (Fig. 7(c)), dark gray particles were formed in the glasses penetrated into PZT and adjacent to the reaction zone. Figure 10 shows the EPMA result. The dark gray particles contain $\mathrm{Pb}, \mathrm{Si}$, and $\mathrm{Zr}$, and are judged to be phase $\mathrm{X}$. Phase $\mathrm{X}$ precipitates during cooling, as in the case of the slowly-cooled PZT/ PS60 sample.

3.3 Effect of glass composition

The phase relation and interfacial microstructure are affected by the amount of $\mathrm{PbO}$ dissolved in the glass melt from $\mathrm{PZT}$, and this amount of $\mathrm{PbO}$ is determined by the activity of $\mathrm{PbO}$ in the glass melt and PZT, as explained in Part 1 of the present paper. ${ }^{1}$ The activity of $\mathrm{PbO}$ in the glass melt is determined by the $\mathrm{PbO}$ concentration and the $\mathrm{B}_{2} \mathrm{O}_{3} /$ $\mathrm{SiO}_{2}$ ratio. ${ }^{7)}$ The activity of $\mathrm{PbO}$ is higher and the amount of $\mathrm{PbO}$ dissolved in the glass phase is smaller in the melt containing $60 \mathrm{~mol} \%$ of $\mathrm{PbO}$ than in that containing $40 \mathrm{~mol} \%$ of $\mathrm{PbO}$. Thus, the concentration of the constituent oxides of PZT does not exceed the solubility limit in the PZT/PS60 sample, and no solid product forms at $850^{\circ} \mathrm{C}$. In the PBS60 glass melt, the activity of $\mathrm{PbO}$ is reduced by substituting $\mathrm{B}_{2} \mathrm{O}_{3}$ for $\mathrm{SiO}_{2},{ }^{7}$ ) and the amount of $\mathrm{PbO}$ dissolved in the glass melt is larger than that in the PZT/PS60 sample. The concentration of the constituent oxides of PZT exceeds the solubility limit and Ti-rich PZT and $\mathrm{ZrO}_{2}$ particles form.

In the PZT/PS40 sample, the amount of $\mathrm{PbO}$ dissolved in the glass melt is larger than that in the PZT/PS60 sample.
The $\mathrm{ZrO}_{2}$ concentration exceeds the solibility limit and $\mathrm{ZrO}_{2}$ particles precipitate. In the PBS40 glass melt, the activity of $\mathrm{PbO}$ in the glass melt is much reduced from that in the PS40 glass melt by substituting $\mathrm{B}_{2} \mathrm{O}_{3}$ for $\mathrm{SiO}_{2}$. Thus, the amount of $\mathrm{PbO}$ dissolved in the glass melt from $\mathrm{PZT}$ is large, resulting in the formation of the thick reaction zone composed of Ti-rich PZT and $\mathrm{ZrO}_{2}$ particles.

The shape of phase X was different in the PZT/PS60 and PZT/PBS60 samples cooled slowly (Figs. 1(c) and 8(c)). This compound precipitates from the melt during cooling from $850^{\circ} \mathrm{C}$ to room temperature. The difference in the shape might be caused by the viscosity of the melt; the PBS60 glass has smaller viscosity than the PS60 glass. ${ }^{8)}$ When the viscosity is small, the diffusion rate is large and ions can easily move in the melt and also along the interface between a precipitated particle and melt. In this case, the particle surface with low interfacial energy can easily develop. Thus, the particles with habit form in the PZT/ PBS60 sample.

\section{Conclusions}

The chemical reaction between $\mathrm{Pb}\left(\mathrm{Zr}_{0.53} \mathrm{Ti}_{0.47}\right) \mathrm{O}_{3}$ and the glasses in the $\mathrm{PbO}-\mathrm{SiO}_{2}$ and $\mathrm{PbO}-\mathrm{B}_{2} \mathrm{O}_{3}-\mathrm{SiO}_{2}$ systems was studied for powder and bulk PZT samples at $850^{\circ} \mathrm{C}$. The amount of PZT dissolved in the glass was smaller in the $\mathrm{PbO}-\mathrm{SiO}_{2}$ glasses than in the $\mathrm{PbO}-\mathrm{B}_{2} \mathrm{O}_{3}$ glasses (Part ${ }^{1}{ }^{1}$ ) with the same $\mathrm{PbO}$ content, resulting in the formation of thin reaction zone between PZT and the glass phase, for which the higher activity of $\mathrm{PbO}$ in the $\mathrm{PbO}-\mathrm{SiO}_{2}$ glasses than in the $\mathrm{PbO}-\mathrm{B}_{2} \mathrm{O}_{3}$ glasses was responsible. The solid reaction products were a compound in the $\mathrm{PbO}-\mathrm{SiO}_{2}-\mathrm{ZrO}_{2}$ system (phase $\mathrm{X}$ ) and $\mathrm{ZrO}_{2}$ in the PZT/PS40 samples obtained for powder and bulk PZT, respectively. The degree of supersaturation of $\mathrm{ZrO}_{2}$ determined the phase of solid product. In the $\mathrm{PZT} / \mathrm{PS} 60$ sample obtained by the reaction of bulk PZT, no solid reaction product formed at $850^{\circ} \mathrm{C}$, and phase $\mathrm{X}$ precipitated during cooling to room temperature.

The substitution of $\mathrm{B}_{2} \mathrm{O}_{3}$ for $\mathrm{SiO}_{2}$ in the glass melt increased the amount of PZT dissolved in the glass, for which a decrease in the activity of $\mathrm{PbO}$ in the glass melt is responsible. Ti-rich PZT and $\mathrm{ZrO}_{2}$ particles formed in the reaction zone in the PZT/PBS40 and PZT/PBS60 samples. The PBS40 glass formed the thicker reaction zone than the PBS 60 glass. In the PZT/PBS60 sample, phase X precipitated during cooling.

\section{References}

1) Purwasasmita, B. S. and Kimura, T., J. Ceram. Soc. Japan, 108, 966-72(2000).

2) "Phase Diagrams for Ceramists, Vol. 1," Ed. by Levin, E. M., Robbins, C. R. and McMardie, H. M., The American Ceramic Society, Columbus, Ohio (1964) Fig. 284.

3) "Phase Diagrams for Ceramists, Vol. 1," Ed. by Levin, E. M., Robbins, C. R. and McMardie, H. M., The American Ceramic Society, Columbus, Ohio (1964) Fig. 740.

4) Imaoka, M., Yamazaki, T. and Yasui, I., Rep. Inst. Ind. Sci. Univ. Tokyo, 31, 59-101 (1984).

5) JCPDS File, Nos. $30-723$ and 30-726.

6) Houng, B. and Haun, M. J., Ferroelectrics, 154, 107-12 (1994).

7) Wang, Z. C., Tian, Y. W., Yu, H. L., Zhang, X. H. and Zhou, J. K., Metall. Mater. Trans. B, 25B, 103-09 (1994).

8) Kubota, K., Masuda, H., Fujino, S. and Morinaga, K., J. Ceram. Soc. Japan, 106, 909-13 (1998) [in Japanese]. 